\title{
Cyberbullying: Responsibility, Concerns and Personal Experiences of School-based Speech-Language Pathologists
}

\author{
Gordon W. Blood, Ingrid M. Blood \\ The Pennsylvania State University \\ Pennsylvania, USA
}

\begin{abstract}
This study examined the perceived responsibility and concerns about cyberbullying of 1,884 schoolbased speech-language pathologists (SLPS) in the United States. Factor analysis of a newly developed scale for SLPs and cyberbullying was conducted. Four factors accounting for $62.4 \%$ of the total variance were labeled 1) SLPS' roles and responsibilities, 2) Schools' roles and responsibilities, 3) SLPs' knowledge and confidence, and 4) Student behaviors and responses. Results showed a majority of SLPs reported cyberbullying was problematic; expressed concerns about the negative impact; endorsed schools taking responsibility, leadership and action for activities and assisting victims. In contrast, a minority of SLPS reported confidence in identifying or managing cyberbullying; satisfaction with current continuing education; and any role in addressing cyberbullying in their own treatment sessions. Two groups of SLPS were created based on whether or not students disclosed directly to them any type of bullying incidents, including cyberbullying. Significant differences were found on 9 of the 26 items between the groups. SLPs reporting students disclosing to them about bullying were stronger advocates for involvement in bullying issues. The data should be valuable to pre-service and in-service educators designing training programs. Results should assist school counselors, administrators and leaders implementing effective school-wide cyberbullying initiatives.
\end{abstract}

\section{Introduction}

All school personnel play critical roles in students' academic, social and emotional development. According to the American SpeechLanguage-Hearing Association's Position Statement on "Roles and Responsibilities of Speech-Language Pathologists in Schools", speech-language pathologists (SLPs) address personal, social/emotional, academic, and vocational needs that have an impact on attainment of educational goals of students with disabilities [1]. Cyberbullying is a serious health and educational problem which interferes with students' educational goals. Researchers disagree over the operational definition of cyberbullying due to its similarities and differences to traditional bullying and cyber aggression. Many researchers utilize Tokunaga's definition [2] as "any behavior performed through electronic or digital media by individuals or groups that repeatedly communicate hostile or aggressive messages intended to inflict harm or discomfort on others"'(p. 278). Modecki and colleagues [3] in a recent meta-analyses of studies on cyberbullying reported that the prevalence of cyberbullying in school-age children and youth is about $15 \%$ compared with around $35 \%$ for traditional bullying (i.e., physical, verbal and relational). Cyberbullies may actually cause greater harm than traditional bullies because of the bully's anonymity, unlimited access to targets, potential for impersonation and an infinite number of bystanders [4-5]. Cyberbullying takes place using a medium in which adults are not present. This makes identification, management and effective interventions very difficult. It is imperative that school personnel are educated and made aware of new problems associated with emerging communication and technology in a digital age of learning, including cyberbullying to effectively manage these problems [6-8].

Students with disabilities are more vulnerable to victimization and bullying than their non-disabled peers. This includes students with physical, psychological, communication and social disabilities [9-11]. These students become targets for bullying due to the type, visibility, severity and negative stereotypes held about their disabilities by their peers. Oftentimes, physical, psychological, intellectual and sensory disabilities are accompanied by additional social and communication problems.

Researchers suggest that school-based SLPs can be effective members of support systems for bullying 
victims [11-16]. The reasons for their involvement include the fact that SLPs create safe and supportive environments for students when they are engaged in the remediation of communication and social disabilities. Their services are often with only one student at a time outside the observation of teachers, administrators and parents. This allows SLPs to offer support and engage in positive relationships with students on their caseloads, foster safe and nurturing learning environments and contribute to the social inclusion and self-esteem of children with disabilities. In addition, they serve as adult advocates for students at Individualized Education Program (IEP) meetings and work collaboratively with classroom teachers inside the classroom environment, especially in the areas of language and literacy.

Before effective management and treatment programs for dealing with cyberbullying by schoolbased personnel are developed and implemented, a number of questions should be addressed. These include: school personnel's information about the nature of cyberbullying; concerns about who is responsible for managing the problem; what type of pre-service and professional development programs would boost their confidence and what practices, policies or initiatives do school personnel believe would be effective in reducing and eliminating cyberbullying in schools.

Effective programs involving SLPs should address their specific needs and structure learning opportunities based on their current knowledge and skills. There are currently few standardized protocols for evaluating cyberbullying in school personnel and none for school-based SLPs. This study created a theory based scale using new items and adapting previous items from protocols for preservice, elementary and secondary teachers. These data may provide support for SLPs' involvement in identifying and managing cyberbullying. It should also provide new information describing evolving professional practices for SLPs on new collaborative teams and enhanced advocacy roles for students with communication and social disabilities.

The purpose of this study was to examine these issues from one group of potential members of school-based initiatives and support teams led by school psychologists, counselors, teachers and administrators. In addition, SLPs were divided into two groups based on self-reports of whether or not students had disclosed bullying incidents directly to them. It was hypothesized that SLPs who reported students disclosed bullying incidents directly to them would have more knowledge about bullying, greater willingness to assist students, more likely to support administrative school-based initiatives, more likely support school counseling interventions and more likely to report cyber bullying intervention was within their scope of practice.

\section{Methods}

The methods and procedures for this study are similar to those in our earlier published work [1214]. Readers are directed to those studies for greater details. Briefly, a mail survey study using a random, proportional, stratified, probability sampling technique was conducted. The surveys included: a) a brief description of the study, b) the informed consent procedures, c) demographic information (e.g., age, gender, race/ethnicity), d) practice-related items (e.g., experience, work location, number of students) and e) study questions, scales, and vignettes. Participants received 2, 4, and 8 week follow-up mailings after the first mailing to increase responses.

\subsection{Participants}

A random, computerized list of 4,000 names was generated by and purchased from the American Speech-Language-Hearing Association's (ASHA) mailing lists targeting certified SLPs employed in public schools residing in the United States. After eliminating unusable surveys due to returned surveys, change of addresses, incomplete data, parttime employment, etc., 1,884 responses were obtained. This represented a $47.1 \%$ response rate.

Participants included 1,792 $(95.1 \%)$ females and $92(4.9 \%)$ males ranging in age from 26-65 years (mean age of 42.7, S.D. = 11.4). SLPs self-identified as white, non-Hispanic (82.9\%), African American (8.6\%), Hispanic American (5.4\%), Asian American $(2.2 \%)$ while $(0.9 \%)$ self-identified from other racial/ethnic origins. A mean caseload size for participants was 49.7 with a range from 19 to 91 children. SLPs worked a mean of 17.4 years (S.D. = 11.2). SLPs reported on their primary geographic work setting. This revealed $17.8 \%$ worked in rural areas, $44.1 \%$ in suburban areas, and $38.1 \%$ in urban areas of $100,000+$ individuals.

\subsection{Scale}

This study is part of a larger study examining SLPs' perceptions and attitudes about bullying in schools. There is currently no measure available to examine the perceived attitudes, responsibilities, concerns and perspectives of school-based SLPs and cyberbullying. A series of statements were designed by the authors based on a thorough review of the literature and adapting items from previous scales designed for pre-service, elementary and secondary school teachers about cyberbullying [17-19]. After conducting a focus group of 19 SLPs to obtain information, current views and questions about cyberbullying, we developed 41 statements for inclusion in the scale. These statements were validated by a different group of 25 randomly 
selected SLPs using the process reported in our earlier studies [12-14]. This included the first author reviewing judges' comments, opinions, suggested word changes and then included these changes in the final version. We eliminated seven redundant or confusing statements based on SLPs feedback at this stage of the process.

In order to determine the latent structure of the remaining 34 statements, an exploratory factor analysis was conducted. A principal component factor analysis with a varimax rotation using eigenvalues of the factors set at greater than 1 , with no factor loading $<.40$ was computed. Items would only be included in a single factor. The analysis revealed a scale with a four-factor structure accounting for $62.4 \%$ of the total variance with 26 statements.

Factor one was labeled "SLPs' Roles and Responsibilities", consisted of eight items and accounted for $24.8 \%$ of the total variance. These items included: 1) SLPs should organize therapy activities to deal with cyberbullying; 2) My SLP inservice training and other continuing education activities have prepared me to identify and deal with cyberbullying; 3 ) Cyberbullying and other acts of aggression are outside the scope of practice for me as an SLP and should be handled by other school personnel; 4) Other school personnel are much better prepared, qualified and knowledgeable about dealing with cyberbullying than I am as a school-based SLP; 5) As a school-based SLP, my responsibility would be to support the student by listening and ensuring the student's safety; 6) As a school-based SLP, my responsibility would be to support the student by reporting the problem immediately and following school policies; 7) As an SLP, my responsibilities include creating and maintaining a safe and nurturing learning environment for all students; 8) As a schoolbased SLP, if I knew cyberbullying was occurring in school I would do something to intervene and stop the cyberbullying.

Factor two was labeled "School's Roles and Responsibilities", consisted of eight items and accounted for $16.5 \%$ of the total variance. These items included: 1) Schools should develop policies on cyberbullying; 2) Teachers should organize classroom activities to deal with cyberbullying; 3 ) School administrators should organize school wide activities to identify, reduce and eliminate cyberbullying; 4) School counselors should organize activities to identify, reduce and eliminate cyberbullying; 5) Schools should discuss cyberbullying with families; 6) If cyberbullying takes place outside school grounds and classes, the school has no authority or responsibility to deal with cyberbullying; 7) Schools should provide student victims with counseling to help cope with cyberbullying and 8) School resources should be used to assist all school personnel to manage cyberbullying

Factor three was labeled "Knowledge and Confidence", consisted of six items and accounted for $11.4 \%$ of the total variance. These items included: 1) Cyberbullying is a problem in the school(s) where I provide services; 2) I am concerned about cyberbullying and our students; 3) I feel confident in identifying cyberbullying; 4) I feel confident in managing cyberbullying; 5) I want to learn more about cyberbullying and 6) Cyberbullying often takes place both inside and outside school grounds and classes which makes more difficult to deal with than traditional bullying (i.e. physical, verbal, relational).

Factor four was labeled "Student Behaviors and Responses", consisted of four items and accounted for $9.7 \%$ of the total variance. These items included: 1) Students usually report cyberbullying incidents to me when they happen; 2) Students actively seek help when being bullied online; 3) Student's educational, psychological physical and vocational development are negatively affected by cyberbullying and 4) Students deliberately conceal the fact of their being bullied online. Table 1 provides a summary of the factor analyses.

In addition, Cronbach's alpha, a measure of internal consistency and scale reliability was also computed. This is a common method of checking the internal consistency of a group of items. The Cronbach alpha coefficient for each of the four factors of the scale was determined. Cronbach alpha coefficients were $0.84,0.88,81$ and 0.83 for Factors $1,2,3$, and 4 respectively. These coefficients were greater than 0.80 , suggesting good reliability.

Finally, SLPs used a 5-point Likert rating scale from 1 (Strongly Disagree), 2 (Disagree), 3 (Neither Agree/Disagree), 4 (Agree), to 5 (Strongly Agree) for each item.

\subsection{Procedures}

Procedures paralleled those in earlier studies [1214]. Participants were mailed an introductory letter (with informed consent), a detailed survey requesting information on demographic and practice variables, a series of scales and questionnaires, the current 26item scale and a return envelope.

To standardize procedures, the term cyberbullying was defined at the top of the page of the 26-item scale in bold print. The following statement was provided: "Cyberbullying is defined as any behavior performed through electronic or digital media by individuals or groups that repeatedly communicate hostile or aggressive messages intended to inflict harm or discomfort on others" [2]. Participants were instructed to read the cyberbullying definition and complete the 26-item scale. 
Table 1. Factor analysis loadings and the resulting 26 items that were retained

\begin{tabular}{|c|c|c|c|c|}
\hline Items & Factor 1 & Factor 2 & Factor 3 & Factor 4 \\
\hline 1. SLPs should organize therapy activities to deal with cyberbullying & 0.82 & & & \\
\hline $\begin{array}{l}\text { 2. My SLP in-service training and other continuing education } \\
\text { activities have prepared me to identify and deal with } \\
\text { cyberbullying }\end{array}$ & 0.78 & & & \\
\hline $\begin{array}{l}\text { 3. Cyberbullying and other acts of aggression are outside the scope } \\
\text { of practice for me as an SLP and should be handled by other } \\
\text { school personnel }\end{array}$ & 0.74 & & & \\
\hline $\begin{array}{l}\text { 4. Other school personnel are much better prepared, qualified and } \\
\text { knowledgeable about dealing with cyberbullying than I am as a } \\
\text { school-based SLP }\end{array}$ & 0.81 & & & \\
\hline $\begin{array}{l}\text { 5. As a school-based SLP, my responsibility would be to support the } \\
\text { student by listening and ensuring the student's safety }\end{array}$ & 0.77 & & & \\
\hline $\begin{array}{l}\text { 6. As a school-based SLP, my responsibility would be to support the } \\
\text { student by reporting the problem immediately and following } \\
\text { school policies }\end{array}$ & 0.79 & & & \\
\hline $\begin{array}{l}\text { 7. As an SLP, my responsibilities include creating and maintaining a } \\
\text { safe and nurturing learning environment for all students }\end{array}$ & 0.80 & & & \\
\hline $\begin{array}{l}\text { 8. As a school-based SLP, if I knew cyberbullying was occurring in } \\
\text { school I would do something to intervene and stop the } \\
\text { cyberbullying. }\end{array}$ & 0.74 & & & \\
\hline 9. $\quad$ Schools should develop policies on cyberbullying & & 0.79 & & \\
\hline $\begin{array}{l}\text { 10. Teachers should organize classroom activities to deal with } \\
\text { cyberbullying }\end{array}$ & & 0.72 & & \\
\hline $\begin{array}{l}\text { 11. School administrators should organize school wide activities to } \\
\text { identify, reduce and eliminate cyberbullying }\end{array}$ & & 0.65 & & \\
\hline $\begin{array}{l}\text { 12. School counselors should organize activities to identify, reduce } \\
\text { and eliminate cyberbullying }\end{array}$ & & 0.76 & & \\
\hline 13. Schools should discuss cyberbullying with families & & 0.74 & & \\
\hline $\begin{array}{l}\text { 14. If cyberbullying takes place outside schools grounds and classes, } \\
\text { the school has no authority or responsibility to deal with } \\
\text { cyberbullying }\end{array}$ & & 0.77 & & \\
\hline $\begin{array}{l}\text { 15. Schools should provide student victims with counseling to help } \\
\text { cope with cyberbullying }\end{array}$ & & 0.67 & & \\
\hline $\begin{array}{l}\text { 16. School resources should be used to assist all school personnel deal } \\
\text { with cyberbullying }\end{array}$ & & 0.79 & & \\
\hline $\begin{array}{l}\text { 17. Cyberbullying is a problem in the school(s) where I provide } \\
\text { services }\end{array}$ & & & 0.74 & \\
\hline 18. I am concerned about cyberbullying and our students & & & 0.73 & \\
\hline 19. I feel confident in identifying cyberbullying & & & 0.76 & \\
\hline 20. I feel confident in managing cyberbullying & & & 0.79 & \\
\hline 21. I want to learn more about cyberbullying & & & 0.61 & \\
\hline 22. Cyberbullying often takes place both inside and outside school & & & 0.67 & \\
\hline
\end{tabular}




\begin{tabular}{|c|c|}
\hline $\begin{array}{l}\text { grounds and classes which makes more difficult to deal with than } \\
\text { traditional bullying (i.e. physical, verbal, relational) }\end{array}$ & \\
\hline $\begin{array}{l}\text { 23. Students usually report cyberbullying incidents to me when they } \\
\text { happen }\end{array}$ & 0.79 \\
\hline 24. Students actively seek help when being bullied online & 0.69 \\
\hline $\begin{array}{l}\text { 25. Student's educational, psychological physical and vocational } \\
\text { development are negatively affected by cyberbullying }\end{array}$ & 0.81 \\
\hline 26. Students deliberately conceal the fact of their being bullied online. & 0.70 \\
\hline
\end{tabular}

\subsection{Grouping Analysis}

For this study, we also used the data from two survey questions to group participants for additional analyses. The survey questions were "Have any students told you personally about a bullying (i.e. physical, verbal, relational or cyber) incident?" The follow-up question for those SLPs who responded affirmatively was "Have any students told you personally about a cyber bullying incident?" SLPs were provided a binary choice, Yes or No. Responses to the first survey question "Have any students told you personally about a bullying (i.e. physical, verbal, relational or cyber) incident?" revealed that $1625(86.3 \%)$ responded "No" and 259 (13.7\%) responded "Yes".

SLPs who responded "Yes" to the first question were asked to respond to a second question "Have any students told you personally about a cyber bullying incident?" The analysis showed that 105 (5.6\%) SLPs reported that students had reported cyberbullying incidents directly to them.

Based on these results, two groups were created. Group $1(\mathrm{n}=1625)$ consisted of SLPs who responded they had NO students disclose directly to them any type of bullying incidents. Group 2 (259) consisted of SLPs who responded they had students disclose ANY type of bullying incidents to them directly.

A series of t-tests were computed on age, gender, race/ethnicity, years of work experience and caseload size between the two groups. To reduce the likelihood of making a Type I error, a Bonferroni correction was used. The significant level was set at $\mathrm{p}<.05$. No significant differences were found on any of the demographic and practice-related variables between the groups.

\subsection{Data Analysis}

A series of $26 \mathrm{t}$-tests were computed between the two groups to determine significant differences. Due to the large number of t-test conducted, a Bonferroni correction was used to reduce the likelihood of making a Type I error for each of the four factors. In addition, to calculate the effect size, Hedges' $g$ was used. This is the recommended effect size calculation by Cohen for unequal sample sizes. It makes an adjustment for the sample sizes by calculating the pooled standard deviation with weights for the sample sizes [20]. The standard interpretation offered by Cohen of effect size is also used for Hedges' where 0.2 represents a "small" effect size, 0.5 represents a "medium" effect size and 0.8 a "large" effect size.

\section{Results}

\subsection{Percent Agreement/Disagreement}

SLPs rated the 26 items on a five point disagreement/agreement scale. As a group SLPs "Agreed" (Strongly Agree $=5.0$ or Agree $=4.0$ ) with $12(46 \%)$ of the 26 items in Table 1 . These included items: $4,5,6,7,8,9,10,11,12,17,18$, and 25 . For nine $(35 \%)$ of the 26 items, SLPs reported they were uncertain (Neutral/Unsure $=3.0$ ) about their responses. These items included: 3, 13, 14, 15, 16, 21, 22, 24, and 26. Finally, SLPs as a group "Disagreed" (Strongly Disagree $=1$ or Disagree $=2$ ) with 5 (19\%) items including 1, 2, 19, 20, and 23.

\subsection{Differences between Groups}

There were significant differences between the two groups on 9 of the 26 items. The means and standard deviations for items in Factor 1 are presented in Table 2. A series of t-tests were computed between the groups. A Bonferroni correction was used and the significance level was set at $\mathrm{p}<.006(.05 / 8)$. Results revealed SLPs with students disclosing bullying incidents to them reported significantly greater disagreement than SLPs with no students disclosing for the statement "Cyberbullying and other acts of aggression are outside the scope of practice for me as an SLP and should be handled by other school personnel", ( $\mathrm{t}$ $(1883)=31.92 ., \mathrm{p}=.001$, Hedges' $\mathrm{g}=1.29)$. 
Significant differences were found for only one of the eight statements between the two groups.

The means and standard deviations for items in Factor 2 are presented in Table 3. A series of t-tests were computed between the groups. The Bonferroni correction was used and the significance level was set at $\mathrm{p}<.006(.05 / 8)$. Results revealed SLPs with students disclosing bullying incidents to them reported significantly greater agreement than SLPs with no students disclosing for the statement "Schools should discuss cyberbullying with families", $(\mathrm{t}(1883)=15.59, \mathrm{p}=.001$, Hedges' $\mathrm{g}=$ 1.01). Similarly, SLPs with students disclosing bullying incidents to them reported significantly greater agreement than SLPs with no students disclosing for the statement "Schools should provide student victims with counseling to help cope with cyberbullying", $(\mathrm{t}(1883)=37.40, \mathrm{p}=.001$, Hedges' $\mathrm{g}=1.41$ ) and the "School resources should be used to assist all school personnel deal with cyberbullying", $(\mathrm{t}(1883)=25.38, \mathrm{p}=.001$, Hedges' $\mathrm{g}=1.43$ ). SLPs with students disclosing bullying incidents to them reported significantly greater disagreement than SLPs with no students disclosing for the statement "If cyberbullying takes place outside schools grounds and classes, the school has no authority or responsibility to deal with cyberbullying " $(\mathrm{t}(1883)=22.18, \mathrm{p}=.001$, Hedges' $\mathrm{g}=1.14$ ). Significant differences were found for four of the eight statements between the two groups, all of them with large effect sizes.

The means and standard deviations for items in Factor 3 are presented in Table 4. A series of t-tests were computed between the groups. The Bonferroni correction was used and the significance level was set at $\mathrm{p}<.008(.05 / 6)$. Results revealed SLPs with student cyberbullying disclosure reported significantly greater agreement than SLPs with no student cyberbullying disclosure for three of the six items. Both SLP groups reported agreement with the item "Cyberbullying is a problem in the school(s) where I provide services", however, SLPs with students disclosing bullying incidents to them reported significantly greater agreement $(\mathrm{t}(1883)=$ 17.91, $\mathrm{p}=.001$, Hedges' $\mathrm{g}=0.61$ ). Similarly, both groups of SLPs agreed with the item "I am concerned about cyberbullying and our students", however, SLPs with students disclosing bullying incidents to them reported significantly greater agreement $(\mathrm{t}(1883)=23.95, \mathrm{p}=.001$, Hedges' $\mathrm{g}=$ 0.85). SLPs with students disclosing bullying incidents to them reported significantly greater disagreement than SLPs with no students disclosing for the item "I want to learn more about cyberbullying”, $(\mathrm{t}(1883)=34.83, \mathrm{p}=.001$, Hedges' $\mathrm{g}=1.25)$.

The means and standard deviations for items in Factor 4 are presented in Table 5. A series of t-tests were computed between the groups. The Bonferroni correction was used and the significance level was set at $p<.012(.05 / 4)$. Both groups of SLPs strongly disagreed with the item "Students usually report cyberbullying incidents to me when they happen". Both groups of SLPs responded using the unsure category for the statement "Students actively seek help when being bullied online", while both groups agreed with the item "Student's educational, psychological physical and vocational development are negatively affected by cyberbullying". However, SLPs with students disclosing bullying incidents to them reported greater agreement about negative impact $(\mathrm{t}(1883)=17.46, \mathrm{p}=.001$, Hedges' $\mathrm{g}=$ $0.64)$.

\section{Discussion}

The purpose of the study was to examine SLPs' perceptions of responsibility, their concerns, confidence levels, attitudes and preparation for identifying and managing cyberbullying. A 26-item scale was developed and factor analyzed using new items culled from the literature and adapting items from previous scales with pre-service teachers and elementary and secondary teachers. The scale was administered to two groups of SLPs. The largest group $(n=1659)$ consisted of SLPs reporting NO students disclosing bullying incidents directly to them. The smaller group $(n=259)$ consisted of SLPs reporting students disclosing bullying incidents directly to them.

The first important finding was that $13.7 \%$ of the SLPs reported students disclosing bullying incidents directly to them. More than one of every ten SLPs reported students disclosed to them about bullying. SLPs are in a unique role of being able to create "safe environments" for some students who feel comfortable and secure enough to disclose bullying incidents to them directly. The literature is replete with data stating consistently that students tend not to report bullying incidents to teachers and schoolpersonnel. Cyberbullying is even less likely to be reported due to the possibility of the technology being removed or the belief that nothing can be done to assist students. This findings has implications for school leaders establishing and maintaining schoolwide initiatives in reducing and eliminating all types of bullying. Although teachers, school counselors, school social workers and school psychologists are usually involved in these initiatives, SLPs working in the schools may also be a valuable overlooked team resource.

Another important finding is the reliability and validity of a new scale for examining these perceptions with SLPs. The 26-item scale with four unidimensional factors and good internal consistency may be useful for other researchers, administrators or school leaders engaged in pre- and post-test measures with specific anti-bullying training 
Table 2. Means and standard deviations for the two groups of SLPs for Factor 1

\begin{tabular}{|c|c|c|c|c|}
\hline \multirow[t]{2}{*}{ Factor 1: SLPs' Roles and Responsibilities } & \multicolumn{2}{|c|}{$\begin{array}{l}\text { SLPs reporting No } \\
\text { student cyberbullying } \\
\text { disclosure }(n=1625)\end{array}$} & \multicolumn{2}{|c|}{$\begin{array}{l}\text { SLPs reporting student } \\
\text { cyberbullying disclosure } \\
(\mathrm{n}=259)\end{array}$} \\
\hline & Mean & $\begin{array}{l}\text { Standard } \\
\text { Deviation }\end{array}$ & Mean & $\begin{array}{l}\text { Standard } \\
\text { Deviation }\end{array}$ \\
\hline $\begin{array}{l}\text { 27. SLPs should organize therapy activities to deal with } \\
\text { cyberbullying }\end{array}$ & 1.7 & 0.8 & 1.6 & 0.7 \\
\hline $\begin{array}{l}\text { 28. My SLP in-service training and other continuing } \\
\text { education activities have prepared me to identify } \\
\text { and deal with cyberbullying }\end{array}$ & 2.3 & 1.1 & 2.3 & 1.1 \\
\hline $\begin{array}{l}\text { 29. Cyberbullying and other acts of aggression are } \\
\text { outside the scope of practice for me as an SLP and } \\
\text { should be handled by other school personnel }\end{array}$ & $3.5^{*}$ & 1.2 & $1.9 *$ & 0.7 \\
\hline $\begin{array}{l}\text { 30. Other school personnel are much better prepared, } \\
\text { qualified and knowledgeable about dealing with } \\
\text { cyberbullying than I am as a school-based SLP }\end{array}$ & 4.6 & 0.9 & 4.5 & 0.7 \\
\hline $\begin{array}{l}\text { 31. As a school-based SLP, my responsibility would be } \\
\text { to support the student by listening and ensuring the } \\
\text { student's safety }\end{array}$ & 4.3 & 0.7 & 4.3 & 0.7 \\
\hline $\begin{array}{l}\text { 32. As a school-based SLP, my responsibility would be } \\
\text { to support the student by reporting the problem } \\
\text { immediately and following school policies }\end{array}$ & 4.7 & 0.7 & 4.8 & 0.5 \\
\hline $\begin{array}{l}\text { 33. As an SLP, my responsibilities include creating and } \\
\text { maintaining a safe and nurturing learning } \\
\text { environment for all students }\end{array}$ & 4.7 & 0.7 & 4.8 & 0.5 \\
\hline $\begin{array}{l}\text { 34. As a school-based SLP, if I knew cyberbullying } \\
\text { was occurring in school I would do something to } \\
\text { intervene and stop the cyberbullying. }\end{array}$ & 4.6 & 0.8 & 4.7 & 0.6 \\
\hline
\end{tabular}

*indicates a significant difference $\mathrm{p}<.001$.

Table 3. Means and standard deviations for the two groups of SLPs for Factor 2

\begin{tabular}{|l|l|l|l|l|}
\hline Factor 2: Schools' Roles and Responsibilities & \multicolumn{2}{|l|}{$\begin{array}{l}\text { SLPs reporting No } \\
\text { student cyberbullying } \\
\text { disclosure (n=1625) }\end{array}$} & \multicolumn{2}{l|}{$\begin{array}{l}\text { SLPs reporting student } \\
\text { cyberbullying disclosure } \\
\text { (n=259) }\end{array}$} \\
\hline & Mean & $\begin{array}{l}\text { Standard } \\
\text { Deviation }\end{array}$ & Mean & $\begin{array}{l}\text { Standard } \\
\text { Deviation }\end{array}$ \\
\hline $\begin{array}{l}\text { 1. Schools should develop policies on } \\
\text { cyberbullying }\end{array}$ & 4.6 & 0.9 & 4.7 & 0.5 \\
\hline $\begin{array}{l}\text { Teachers should organize classroom activities to } \\
\text { deal with cyberbullying }\end{array}$ & 4.2 & 0.7 & 4.3 & 0.7 \\
\hline 3. $\begin{array}{l}\text { School administrators should organize school wide } \\
\text { activities to identify, reduce and eliminate }\end{array}$ & 4.3 & 0.7 & 4.4 & 0.7 \\
\hline
\end{tabular}




\begin{tabular}{|ll|l|l|l|l|}
\hline \multicolumn{2}{|c|}{ cyberbullying } & & & & \\
\hline 4. & $\begin{array}{l}\text { School counselors should organize activities to } \\
\text { identify, reduce and eliminate cyberbullying }\end{array}$ & 4.1 & 0.9 & 4.1 & 0.9 \\
\hline $5 . \quad$ Schools should discuss cyberbullying with families & $3.3^{*}$ & 1.1 & $4.4^{*}$ & 1.0 \\
\hline $\begin{array}{l}\text { 6. If cyberbullying takes place outside schools } \\
\text { grounds and classes, the school has no authority or } \\
\text { responsibility to deal with cyberbullying }\end{array}$ & $3.4^{*}$ & 1.0 & $2.3^{*}$ & 0.7 \\
\hline 7. & $\begin{array}{l}\text { Schools should provide student victims with } \\
\text { counseling to help cope with cyberbullying }\end{array}$ & $3.3^{*}$ & 1.1 & $4.8^{*}$ & 0.8 \\
\hline 8. $\begin{array}{l}\text { School resources should be used to assist all school } \\
\text { personnel deal with cyberbullying }\end{array}$ & $3.2^{*}$ & 1.0 & $4.6^{*}$ & 0.8 \\
\hline
\end{tabular}

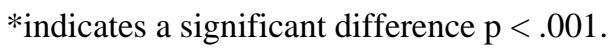

Table 4. Means and standard deviations for the two groups of SLPs for Factor 3

\begin{tabular}{|l|l|l|l|l|}
\hline Factor 3: SLPs' Knowledge and Confidence & \multicolumn{2}{|l|}{$\begin{array}{l}\text { SLPs reporting No } \\
\text { student cyberbullying } \\
\text { disclosure (n=1625) }\end{array}$} & \multicolumn{2}{l|}{$\begin{array}{l}\text { SLPs reporting student } \\
\text { cyberbullying disclosure } \\
\text { (n=259) }\end{array}$} \\
\hline & Mean & $\begin{array}{l}\text { Standard } \\
\text { Deviation }\end{array}$ & Mean & $\begin{array}{l}\text { Standard } \\
\text { Deviation }\end{array}$ \\
\hline $\begin{array}{l}\text { 35. Cyberbullying is a problem in the school(s) where } \\
\text { I provide services }\end{array}$ & $3.9^{*}$ & 1.4 & $4.7^{*}$ & 0.6 \\
\hline $\begin{array}{l}\text { 36. I am concerned about cyberbullying and our } \\
\text { students }\end{array}$ & $4.0^{*}$ & 1.0 & $4.8^{*}$ & 0.4 \\
\hline $\begin{array}{l}\text { 37. I feel confident in identifying cyberbullying } \\
\text { 38. I feel confident in managing cyberbullying }\end{array}$ & 1.6 & 0.7 & 1.5 & 0.5 \\
\hline $\begin{array}{l}\text { 39. I want to learn more about cyberbullying } \\
\text { 40. Cyberbullying often takes place both inside and } \\
\text { outside school grounds and classes which makes } \\
\text { more difficult to deal with than traditional bullying } \\
\text { (i.e. physical, verbal, relational) }\end{array}$ & $3.4^{*}$ & 0.7 & 1.5 & 0.5 \\
\hline
\end{tabular}

*indicates a significant difference $\mathrm{p}<.001$.

Table 5. Means and standard deviations for the two groups of SLPs for Factor 4

\begin{tabular}{|l|l|l|l|l|}
\hline Factor 4: Student Behaviors and Responses & \multicolumn{2}{|l|}{$\begin{array}{l}\text { SLPs reporting No } \\
\text { student cyberbullying } \\
\text { disclosure }(\mathrm{n}=1625)\end{array}$} & $\begin{array}{l}\text { SLPs reporting student } \\
\text { cyberbullying disclosure } \\
(\mathrm{n}=259)\end{array}$ \\
\hline & Mean & $\begin{array}{l}\text { Standard } \\
\text { Deviation }\end{array}$ & Mean & $\begin{array}{l}\text { Standard } \\
\text { Deviation }\end{array}$ \\
\hline
\end{tabular}




\begin{tabular}{|l|l|l|l|l|}
\hline $\begin{array}{l}\text { 41. Students usually report cyberbullying incidents to } \\
\text { me when they happen }\end{array}$ & 1.5 & 0.7 & 1.6 & 0.8 \\
\hline $\begin{array}{l}\text { 42. Students actively seek help when being bullied } \\
\text { online }\end{array}$ & 3.4 & 1.1 & 3.5 & 1.2 \\
\hline $\begin{array}{l}\text { 43. Student's educational, psychological physical and } \\
\text { vocational development are negatively affected by } \\
\text { cyberbullying }\end{array}$ & $4.1^{*}$ & 1.0 & $4.7^{*}$ & 0.4 \\
\hline $\begin{array}{l}\text { 44. Students deliberately conceal the fact of their being } \\
\text { bullied online }\end{array}$ & 3.4 & 0.9 & 3.3 & 0.7 \\
\hline
\end{tabular}

*indicates a significant difference $\mathrm{p}<.001$.

programs. This is the first scale reported to measure attitudes, perceptions, knowledge and perspectives of school-based SLPs and cyberbullying.

\subsection{SLPs' Responses to Specific Items}

The data showed a majority of SLPs (regardless of group) showed agreement or strong agreement with $12(46 \%)$ of the 26 items. The majority of SLPs reported that cyberbullying was a problem in the school(s) where they provided services and that they were concerned about negative impact cyberbullying could have on students' educational, psychological physical and vocational development. This suggests a level of awareness about the potential for harm that cyberbullying can cause. Probably because of these high endorsements (4.0-4.8), the majority of SLPs also reported they perceived their responsibilities as providing support to student victims by listening, creating a safe and nurturing learning environment, reporting the problem immediately and following school policies. They also indicated that if they knew cyberbullying was occurring, they would intervene to stop it. The strong agreement with these items suggest SLPs, as a group, would attempt some type of intervention to stop the cyberbullying if the occasion arose.

It was interesting that the majority of SLPs also agreed or strongly agreed that other school personnel were better prepared, qualified and knowledgeable about dealing with cyberbullying than they were. This may be interpreted as either supporting statements such as cyberbullying issues are "out of their scope of practice" or simply a fact based on their training and current levels of exposure. With current pre-service models, it is not surprising that the majority of SLPs did not feel qualified or prepared to manage issues related to cyberbullying $[11,15]$

SLPs as a group also agreed with the development of school policies, administrative and school counselors' leadership and teachers making cyberbullying part of the curriculum. In stark contrast, the majority saw no room for such activities in their own daily treatment intervention sessions. It may be that SLPs feel their role as a member of the itinerant school personnel excludes them from involvement in discipline-specific activities about cyberbullying. It may also suggest they do not consider this in their "scope of practice" $[11,15]$.

It would be interesting to determine how any school-based personnel would perceive bullying and cyberbullying outside their scope of practice. This could be addressed through in-service training programs for all school-personnel. It is possible that specific school teams are not inclusive in training and collaborating personnel. Future studies using mixed methods research designs including interview and focus groups of SLPs could answer these questions more directly. Future research should also be conducted to determine the evidence of incorporating even a few activities or collaborating with other team members (e.g., counselors, psychologists, teachers) on sustaining classroom activities. These brief SLP-based cyberbullying activities during therapy sessions may strengthen classroom activities and support students and school personnel in building cultures of respect, value, safety and anti-bullying.

A majority of SLPs (regardless of group) also reported the neutral/unsure category for nine (35\%) of the 26 items. The first interesting finding in this category was that the majority of SLPs were unsure about whether cyberbullying and other acts of aggression were outside the scope of practice for school-based SLPs or should be handled by other school personnel. Although the majority of SLPs agreed that creating a safe environment was important and cyberbullying was a harmful and problematic, they were unsure as to their roles and responsibilities in dealing with the problem. Cyberbullying is a serious issue and requires the cooperation of school administrators, personnel and 
parents. These collaborative efforts may assist in reporting cyberbullying incidents and creating safe environments for all students. Professional development for all school personnel is needed for increased knowledge, understanding and awareness.

It appeared SLPs were also unsure about whether these incidents should be handled by other school personnel. It is important to note that when the group analyses were conducted SLPs who reported students had disclosed their bullying incidents to them strongly disagreed $(\mathrm{M}=1.9 ;$ S.D. $=0.7)$ with this statement. Apparently, contact and experience with students changed the opinions of SLPs about their roles and responsibilities to students. This suggests that in-service programs should be enhanced because they appear not to be conveying basic requirements about roles and responsibilities for all school personnel.

Results also showed that SLPs were uncertain about the authority and responsibility of schools if cyberbullying took place off schools grounds and outside classes. It is well documented that most cyberbullying begins in school environment and then moves (due to technology) quickly off school grounds. The neutral responses reported by SLPs suggest that in-service programs for all school personnel, especially SLPs, are warranted.

It was curious that the majority of SLPs were unsure about whether schools should discuss cyberbullying with families, use school resources to assist school personnel in dealing with cyberbullying or that SLPs wanted to learn more about cyberbullying. Again, this suggests that the seriousness of the problem may not be completely understood. SLPs also were uncertain about students who were cyberbullied being provided counseling to help cope with the problem. It should be noted that when the group analyses were conducted SLPs with students who had disclosed their bullying experiences to them strongly agreed $(\mathrm{M}=4.4$; $\mathrm{S} . \mathrm{D}$. = 1.0) that schools should involve families $(\mathrm{M}=4.4$; S.D. = 1.0), school resources should be allocated to assist school personnel about cyberbullying $(\mathrm{M}=$ 4.6; S.D. =0.8), that they wanted to learn more about cyberbullying $(\mathrm{M}=4.7$; $\mathrm{S} . \mathrm{D} .=0.5)$ or that victims should be provided counseling to deal with the cyberbullying $(M=4.8$; S.D. $=0.8)$. Once again, it appears that contact or experience with students disclosing bullying incidents may have changed SLPs' perspectives on how it should be managed and who should be involved.

SLPs also reported uncertainty about how students would respond to cyberbullying. They were not sure whether students actively seek help when being bullied online or whether they deliberately conceal the fact of their being bullied online. These data also support the need for improved understanding and knowledge about cyberbullying through professional development programs and school-wide initiatives.

Finally, a majority of SLPs regardless of group disagreed or strongly disagreed with five $(19 \%)$ of the 26 items A majority of SLPs disagreed or strongly disagreed with the items that stated they were confident in identification and management of cyberbullying incidents; had been properly trained/educated to deal with cyberbullying, that students usually reported cyberbullying incidents directly to them or that they themselves should organize therapy activities to deal with cyberbullying. These data support the notion that SLPs, as a group, think other school personnel should be identifying and managing cyberbullying in schools.

According to Hinduja and Patchin and Hinduja [5] and Troop-Gordon [8] teachers need to be prepared to teach students how to use technology in the classroom while at the same time teaching socially responsible behaviors. However, professional development programs should augment a sound foundation of acquired knowledge and skills, whether for teachers or other school-based personnel. School-based SLPs should receive training about socially responsible behaviors as it is important for working with some of their students (e.g. students with autism spectrum disorders, behavioral disorders, and intellectual disabilities). If SLPs received training in this area at the university level before entering a school environment, it is possible they would feel more confident and prepared in dealing with cyberbullying. That type of training could increase their awareness and understanding of their roles and responsibilities in creating and maintaining safe environment for all students [11].

\subsection{Differences between Groups}

Three of the nine significant differences between the groups were a matter of degree. Both groups agreed with the three statements but SLPs with students disclosing bullying incidents to them reported greater agreement than those who did not report students disclosing. These items were: 1) Cyberbullying is a problem in the school(s) where I provide services, 2) I am concerned about cyberbullying and our students, and 3) Student's educational, psychological physical and vocational development are negatively affected by cyberbullying. It is clear than all SLPs report cyberbullying is a problem which concerns them and can cause harm to a student's general well-being. This is an important finding. SLPs are aware that cyberbullying is associated with various academic and social problems. For SLPs involved in planning individual educational programs for students, the awareness and concern should turn into productive discussions during meetings with other school 
personnel, administrators and family members about the potential bullying or cyberbullying problems for students with communication and social disabilities.

The second set of group differences included three items which SLPs with students disclosing bullying incidents to them reported strong agreement while SLPs reporting no students disclosing to them responded using the neutral or unsure category. These included: 1) Schools should provide student victims with counseling to help cope with cyberbullying, 2) School resources should be used to assist all school personnel deal with cyberbullying, 3) Schools should discuss cyberbullying with families, and 4) I want to learn more about cyberbullying. It is interesting that SLPs with student disclosure strongly agreed with wanting to learn more about cyberbullying, offering counseling services for victims, involving families and using school resources. It appears that having contact with children who have been victims of cyberbullying makes SLPs more aware of the seriousness and devastating consequences of cyberbullying. It also seems that the urgency of the problem requiring collaborative school and family efforts is also understood.

Finally a category of two significant group differences was formed by negative or strong disagreement responses from SLPs with students disclosing bullying incidents to them while SLPs reporting no students disclosing to them responded using the neutral or unsure response. These included: 1) Cyberbullying and other acts of aggression are outside the scope of practice for me as an SLP and should be handled by other school personnel, and 2) If cyberbullying takes place outside schools grounds and classes, the school has no authority or responsibility to deal with cyberbullying. It appears that SLPs with student disclosure experience may have learned about the legal issues and become more aware of their expanding roles in school safety for all students. Oftentimes, having a student disclose any type of serious problem prompts a professional to learn as much as they need to address the problem. SLPs may have "needed" to learn about school policies, initiatives and procedures related to cyberbullying and therefore strongly disagreed with the statements.

All of these differences suggest that professional development workshops and in-service training are needed for SLPs to become more aware of the serious public health and education problem of cyberbullying. As indicated in earlier other research studies, SLPs are in unique roles for assisting victims due to the nature of their work setting. Oftentimes, they meet one-on-one, in face-to-face therapy sessions which include talking about school, home, social and outside activities [12-14]. These spontaneous "revealing or relating moments" in therapy may be the first time a victim begins to share an embarrassing or fearful bullying incident with an adult. An informed SLP with proper education and training may become the gateway in meeting the school's responsibility to assist a vulnerable victim [11-14].

\subsection{Limitations}

The use of self-report survey data, although common, does not necessarily indicate that SLPs would respond in a similar fashion in the "real world" and limits the generalization of the findings. Future research should use qualitative data collection methods and face-to face interviews for understanding such a complex phenomenon as cyberbullying. These methodologies would also allow for a deeper and more thorough understanding of SLPs' responses to questions about cyberbullying in students. Second, this study used data from a single point-in-time while trying to understand a complex and serious public health and education problem. It should also be noted that our respondents volunteered to respond to the survey and may not be representative of the larger population of SLPs.

\section{Conclusion}

A theory-based scale to measure concerns, knowledge, responsibilities and perspectives about cyberbullying was developed and its psychometric characteristics were evaluated in a sample of schoolbased SLPs working in the United States. Results revealed four factors accounting for $62.4 \%$ of the total variance. SLPs reported concern about students and perceived cyberbullying as a problem with potential physical, vocational, academic and psychological negative impact. SLPs were mostly likely to agree about the role of the school administration and other school personnel in leading initiatives against cyberbullying, including additions to the classroom curriculum. They strongly disagreed with integrating cyberbullying activities into their own therapy sessions. They indicated they would stop an incident if it occurred and would report it, following school policies about cyberbullying. The majority of SLPs were unsure or uncertain about their role and responsibilities in dealing with cyberbullying, as well as, whether cyberbullying was within their scope of practice. They reported mixed responses about being adequately prepared and reported that other school personnel were more qualified and knowledgeable about dealing with cyberbullying issues. They were also unsure about the role of counseling victims and involving families. SLPs did not feel confident in their training in this area of identification and management of 
cyberbullying and reported other school personnel should be responsible.

The study also examined the impact of having students disclose bullying incidents directly to SLPs and their responses on the newly developed scale. Two groups of SLPs were formed based on whether or not students had disclosed any type of bullying directly to them. Nearly $14 \%$ of the 1,884 SLPs reported that students had disclosed any type of bullying incidents directly to them. This group reported strong support for school initiatives, use of school resources, counseling for victims, involvement of families and greater awareness of the problem, its negative impact and concern for students than the group who reported no students disclosed bullying incidents directly to them. It appeared that contact with victims of cyberbullying increased awareness and a sense of urgency in dealing with this problem.

The need for continued research on the scale is warranted. Further study is needed to determine if subgroups of SLPs working in specific settings or with specific types of communication and social disabilities have different responses on the scale. The scale may be most appropriate for use with preservice and in-service educational programs that target creating safe environments and specifically cyberbullying for school-based SLPs.

The data suggest a need for enhanced pre-service and in-service programs is necessary if all school personnel are to be part of the solution for managing and eliminating cyberbullying. SLPs may be valuable members of school-wide teams dealing with cyberbullying due to the number children reporting incidents to them directly. They are also good candidates for teams, with further training and experience, because of the safe, one-to-one treatment environments they create and work in with students. These encouraging, safe and protected settings may encourage students to disclose bullying incidents to these concerned adults. With additional training and becoming members of collaborative teams SLPs can play a critical role in responding to and eliminating cyberbullying in all school-age victims, especially those with communication and social disabilities.

\section{References}

[1] American Speech-Language-Hearing Association, "Roles and responsibilities of speech-language pathologists in schools: Professional Issues Statement", (Access date: 15 December 2015) http://www.asha.org/policy/PI2010-00317/\#sec1.2

[2] R.S. Tokunaga, "Following you home from school: A critical review and synthesis of research on cyberbullying victimization", Computers in human behavior, 26, 3, 2010, 277-287.
[3] K.L. Modecki, J. Minchin, A.G. Harbaugh, N.G. Guerra and K.C. Runions "Bullying prevalence across contexts: a meta-analysis measuring cyber and traditional bullying." J adolescent health 55, 2014, 602-611

[4] Kowalski, R.M., S.P. Limber and P.W. Agatston, Cyberbullying: Bullying in the digital age. John Wiley \& Sons, 2012.

[5] Hinduja S. and J.W. Patchin, Bullying beyond the schoolyard: Preventing and responding to cyberbullying. Corwin Press, 2014.

[6] C.S. Bhat "Cyber Bullying: Overview and Strategies for School Counsellors, Guidance Officers, and All School Personnel." Australian j guidance and counsel, 18, 2008, 53-66.

[7] W.V. Pelfrey Jr and N.L. Weber "Student and School Staff Strategies to Combat Cyberbullying in an Urban Student Population." Prev school failure: Alternative education for children and youth, 15, 2014, 1-10.

[8] W. Troop-Gordon "The Role of the Classroom Teacher in the Lives of Children Victimized by Peers." Child devel perspectives 9,1 , 2015, 55-60.

[9] J. Blake, E.M. Lund, Q.Z. Oi-Man Kwok and M.R. Benz, "National prevalence rates of bully victimization among students with disabilities in the United States", School psychology quarterly, 27, 4, 2012, 210-222.

[10] T. Farmer, T.L. Wike, Q.R. Alexander, PC. Rodkin, and M. Mehtaji, "Students with Disabilities and Involvement in Peer Victimization Theory, Research, and Considerations for the Future", Remedial and special education, 36, 2015, 263-274.

[11] G.W. Blood, "Bullying Be Gone", "The ASHA Leader", 19, 5, 2014, 36-42.

[12] G.W. Blood, I.M. Blood, A.D. Coniglio, E.H. Finke and M.P. Boyle, "Familiarity breeds support: Speechlanguage pathologists' perceptions of bullying of students with autism spectrum disorders", Journal of communication disorders, 46, 2, 2013, 169-180.

[13] G.W. Blood, M.P. Boyle, I.M. Blood and G.R. Nalesnik, "Bullying in children who stutter: Speechlanguage pathologists' perceptions and intervention strategies", Journal of fluency disorders, 35, 2, 2010, 92109.

[14] G.W. Blood, K.L. Decker, K.A. Raviotti, A.M. Leibig and I.M. Blood, "Bullying in Schools: Speech Language Pathologists' Responses to Specific Bullying Incidents", Communication disorders, deaf studies and hearing aids, 2, 2014, 121-129.

[15] S. Hughes "Bullying: what speech-language pathologists should know. "Language, speech, and hearing services in schools, 45, 2014, 3-13.

[16] M. Langevin and NG Prasad "A stuttering education and bullying awareness and prevention resource: A 
feasibility study." Language, speech, and hearing services in schools, 43, 2012, 344-358.

[17] W. Cassidy, K. Brown and M. Jackson "'Under the radar': Educators and cyberbullying in schools." School psych international 33, 5, 2012, 520-532.

[18] Q. Li "Cyberbullying in schools: An examination of preservice teachers' perception." Canadian j learning tech, 34, 2, 2008.

[19] S. Stauffer, M.A. Heath, S.M. Coyne and S. Ferrin. "High school teachers' perceptions of cyberbullying prevention and intervention strategies." Psychology in schools 49, 4, 2012, 352-367.

[20] Grissom, R. J. and J.J. Kim. Effect sizes for research: Univariate and multivariate applications. Routledge, 2012. 